\title{
EFFECTS OF ENDWALL GEOMETRY AND STACKING ON TWO-STAGE SUPERSONIC TURBINE PERFORMANCE
}

\author{
Daniel J. Dorney* Lisa W. Griffin ${ }^{\dagger}$ \\ Fluids Dynamics Analysis Branch \\ NASA Marshall Space Flight Center \\ Marshall Space Flight Center, AL, USA
}

\author{
Frank W. Huber ${ }^{\ddagger}$ \\ Riverbend Design Services \\ Palm Beach Gardens, FL, USA \\ Douglas L. Sondak ${ }^{\S}$ \\ Office of Information Technology \\ Boston University \\ Boston, MA, USA
}

\section{INTRODUCTION}

Modern high-work turbines can be compact, transonic, supersonic, counter rotating, and can use a dense drive gas. The vast majority of modern rocket turbine designs fall into these categories. These turbines are often characterized by large amounts of flow unsteadiness. The flow unsteadiness can have a major impact on turbine performance and durability. For ex-

*Aerospace Engineer, Associate Fellow AIAA.

†Team Leader, Senior Member AIAA.

†President, Senior member AIAA.

\$Senior Scientific Programmer, Senior Member AIAA.

Copyright (C)2002 by the American Institute of Aeronautics and Astronautics, Inc. No copyright is asserted in the United States under Title 17, U.S. Code. The U.S. Government has a royalty-free license to exercise all rights under the copyright claimed herein for Governmental Purposes. All other rights are reserved by the copyright owner. 
ample, the Space Transportation Main Engine (STME) fuel turbine, a high-work transonic design, was found to have an unsteady interrow shock which reduced efficiency by 2 points and increased dynamic loading by 24 percent. The Revolutionary Reusable Technology Turbopump (RRTT), which uses full flow oxygen for its drive gas, was found to shed vortices with such energy as to raise serious blade durability concerns. In both cases, the sources of the problems were uncovered before turbopump testing with the application of unsteady computational fluid dynamics (CFD) to the designs. In the case of the RRTT and the Alternate Turbopump Development (ATD) turbines, the unsteady CFD codes were used not just to identify problems, but to guide designs which mitigate problems due to unsteadiness. Using unsteady flow analyses as a part of the design process has led to turbine designs with higher performance and fewer dynamics problems.

Recently, CFD has been used in the design a two-stage supersonic turbine which will be tested experimentally during 2002 [1]-[3]. Simulations, including meanline, two-dimensional CFD and three-dimensional CFD analyses in conjunction with optimization techniques, were used to design both the flowpath and the airfoil geometries. During the course of this work a large separated flow region was detected on the hub endwall between the first-stage vane and the first-stage rotor.

Two methods are commonly used to control the secondary/separated flows (and associated losses) in supersonic turbines: endwall contouring and airfoil stacking. In the current investigation the flow path between the first-stage vanes and rotors, and the stacking of the first-stage vanes were varied in an effort to improve turbine performance. The geometric variations have been studied by performing a series of unsteady three-dimensional numerical simulations for the two-stage turbine.

\section{NUMERICAL ALGORITHM}

The governing equations considered in this study are the time dependent, three-dimensional Reynolds-averaged Navier-Stokes equations. To extend the equations of motion to turbulent flows, an eddy viscosity formulation is used. The turbulent viscosity is calculated using a two-layer algebraic turbulence model.

A time-marching, implicit, finite-difference scheme has been used, which is third-order spatially accurate and second-order temporally accurate. The inviscid fluxes are discretized using a third-order upwind biased scheme. The viscous fluxes are calculated using standard central 
differences. An approximate-factorization technique is used to compute the time rate changes in the conserved variables. Newton sub-iterations are used at each global time step to increase stability and reduce linearization errors. For all cases investigated in this study, two Newton sub-iterations were performed at each time step. Message Passing Interface (MPI) and OpenMP API's have been ued to parallelize the code to reduce the time for large-scale three-dimensional simulations.

The Navier-Stokes analysis uses O- and H-type zonal grids to discretize the flow field and facilitate relative motion of the rotating components. The O-grids are body-fitted to the surfaces of the airfoils and generated using an elliptic equation solution procedure. They are used to properly resolve the viscous flow in the blade passages and to facilitate the application of the algebraic turbulence model. The algebraically-generated H-grids are used to discretize the remainder of the flow field.

The computational analysis has been validated on several supersonic turbine geometries (e.g., Refs. [4] and [5]).

\section{GEOMETRY AND GRIDS}

The two-stage supersonic turbine configuration has 12 first-stage vanes, 30 first-stage rotors, 73 second-stage vanes and 56 second-stage rotors. In the current effort, a 15 -vane/30-rotor/75vane/60-rotor (1/2/5/4) airfoil approximation has been made. To keep the pitch-to-chord ratio (blockage) constant, the first-stage vanes were scaled by a factor of $12 / 15$, the second-stage vanes were scaled by a factor of $73 / 75$ and the second-stage rotors were scaled by a factor of $56 / 60$. The tip clearance in the first- and second-stage rotors was set at the design value of approximately $2.0 \%$ of the respective rotor heights.

The grid densities (number of passages $\times \mathbf{i} \times \mathbf{j} \times \mathbf{k}$ ) for the turbine simulations are presented in Table 1. The total number of grid points used to discretize the turbine was $4,139,957$. The average value of $y^{+}$, the non-dimensional distance of the first grid line above the surface was approximately 1.0 for the airfoil surfaces and 1.5 for the endwall surfaces.

The simulations were run on $24400-\mathrm{MHz}$ R12000 processors of an SGI Origin2000. Each simulation was run for 15.0 global cycles (one complete rotor revolution) at 22,000 time steps per cycle. A global cycle is defined as the time it takes for the two first-stage rotor blades to pass by the first-stage vane airfoil. The value of 22,000 iterations per cycle was chosen to resolve all the expected frequencies of interest. A time step required an average of 9.0 seconds 
CPU time on each of 24 processors. The time periodicity of the solutions was determined by interrogating pressure traces at points along the airfoil surfaces.

\section{NUMERICAL RESULTS}

The two-stage turbine under consideration has a design inlet Mach number of $M_{0}=0.08$, an inlet total pressure of $15.4 \mathrm{MPa}$, and an inlet total temperature of approximately $T_{0}=1236 \mathrm{~K}$. The rotor rotates at $\Omega=31,343 \mathrm{RPM}$, the Reynolds number based on the inlet conditions and the rotor axial chord is approximately $1.2 \times 10^{6}$ and the ratio of the midspan exit static pressure to first-stage vane inlet total pressure is 0.1135 . The operating fluid is hydrogen-rich steam and the average ratio of specific heats is $\gamma=1.3538$.

Four different simulations have been performed to determine the effects of endwall shape and first-stage vane stacking on the performance of the two-stage turbine.

1. Case 1 - Case 1 represents the original turbine geometry based on previous work [1]-[3]. The radius of the inner diameter (ID) and outer diameter (OD) vary linearly from the nominal values in the first-stage vane passage to the final values in the rotor passage. The transition begins about three-quarters of the way between the vane trailing edge and the rotor leading edge, and concludes at the rotor leading edge (see Fig. 1).

2. Case 2 - The radius of the ID and OD vary linearly from the nominal values in the vane passage to the final values in the rotor passage beginning at the vane trailing edge and concluding at the rotor leading edge (see Fig. 1).

3. Case 3 - The radius of the inner diameter (ID) is kept constant at the value used in the rotor. The radius of the $\mathrm{OD}$ varies linearly from the nominal value in the vane passage to the final value in the rotor passage beginning at the vane trailing edge and concluding at the rotor leading edge (see Fig. 1). In this case the height of the vane was increased to keep the vane flow area the same as in Cases 1 and 2.

4. Case 4 - The flow path is identical to that used in Case 3. The vane airfoils are stacked along the trailing edge instead of the center of gravity (as it was in Cases 1,2 and 3). Note, the restacking also gives the vane airfoils an inward radial lean.

Time-averaged velocity vectors in the first-stage vane passage in Case 1 are shown in Fig. 2. The contours show a large region of separated flow extending from the hub to approximately 
$20 \%$ of the span. The axial extent of the region was confined to the area between the vane trailing edge and the rotor leading edge. It was initially theorized that the large separated flow region was being induced by the rapid expansion in the endwall flowpath in Case 1. Reducing the slope of the endwall in Cases 2 and 3, however, did not significantly affect the size of the separated flow region. The next hypothesis was that stacking the vanes along the center of gravity causes the vane throat to point outwards towards the shroud endwall, giving the flow a tendency to pull away from the hub endwall. In particular, the stacking in Cases 1-3 results in a radial flow angle of approximately 23 degrees with respect to the axial direction. Re-stacking the vanes along a radial line connecting the trailing edge points significantly reduced the size of the separated flow region (see Fig. 3).

Tables 2 to 5 contain the area- and time-averaged relative reference frame flow quantities at the inlet and exit of each blade row for all four cases. Area averaged values were used in place of mass averaged values because of the large-scale separation. The calculated value of the reaction is based on the static pressures in each blade row. Some of the relevant information which can be deduced from these tables includes:

- Reducing the size of the separated flow region resulted in an increase in the average vane exit Mach number to 1.37, as compared with 1.17 in Case 1 and 1.15 in Cases 2 and 3.

- Reducing the size of the separated flow region in Case 4 gives a significant increase in turbine efficiency. The increase was in excess of 7 points compared to Case 3 , and nearly 6 points compared to Case 1 . A more detailed comparison of Cases 1 and 4 is presented below.

- The changes made to the first stage had little effect on the flow in the second stage.

- The mass flow was the same in all four cases because the first-stage vane is choked and the throat area was held constant.

Time-averaged radial profiles of the absolute Mach number at the exit of the first-stage vane and rotor in Cases 1 and 4 are shown in Figs. 4 and 5. The Mach number profile at the exit of the first-stage vane (see Fig. 4) clearly shows the extent of the separated flow region. The flow field begins to recover by the time it exits the first-stage rotor (see Fig. 5), and the Mach number profiles were nearly identical in the second stage of the turbine. The presence of tip leakage flow is evident behind the rotor row (see Figs. 5). 


\section{CONCLUSIONS}

A set of unsteady three-dimensional Navier-Stokes simulations has been used to investigate the effects of endwall shape and first-stage vane stacking on the performance of a two-stage supersonic turbine. Re-stacking of the vanes was successfully used to eliminate a large separated/secondary flow region at the hub between the first-stage vanes and rotors. Altering the shape of the endwall in the first stage had little effect on the separated flow region. There was a significant performance increase obtained at the design flow conditions by reducing the separated flow region. It is anticipated that the benefits of improving the behavior of the flow near the endwall will be even greater at off-design operating conditions.

\section{ACKNOWLEDGEMENTS}

The computer time for the flow simulations was provided by NASA Ames Research Center. The authors are especially grateful to Mr. Chuck Niggley for assisting with the use of the computers.

\section{References}

[1] Griffin, L. W., Dorney, D. J., Huber, F. W., Tran, K., Shyy, W., and Papila, N., "Detailed Aerodynamic Design Optimization of an RLV Turbine," AIAA 2001-3397, 37th AIAA/ASME/SAE/ASEE Joint Propulsion Conference, Salt Lake City, UT, July 8-11, 2001.

[2] Papila, N., Shyy, W, Griffin, L. W., Dorney, D. J., "Shape Optimization of Supersonic Turbines Using Response Surface and Neural Network Methods," AIAA 2001-1065, 39th AIAA Aerospace Sciences Meeting and Exhibit, Reno, NV, January 8-11, 2001.

[3] Griffin, L. W., and Dorney, D. J., "RLV Turbine Performance Optimization," PERC 12th Symposium on Propulsion, Cleveland, OH, October 26-27, 2000.

[4] Dorney, D. J., Griffin, L. W., and Huber, F., "A Study of the Effects of Tip Clearance in a Supersonic Turbine," ASME Journal of Turbomachinery, Vol. 122, No. 4, October, 2000, pp. 674-673.

[5] Dorney, D. J., Griffin, L. W., Huber, F., and Sondak, D. L., "Unsteady Flow in a Supersonic Turbine Stage With Variable Specific Heats," AIAA Paper 2001-3884, 37th 
AIAA/ASME/SAE/ASEE Joint Propulsion Conference, Salt Lake City, UT, July 8-11, 2001, also accepted for publication in the AIAA Journal of Propulsion and Power. 


\section{List of Tables}

Table 1. Grid dimensions for the 2-stage turbine.

Table 2. Turbine time-averaged relative flow quantities for Case 1.

Table 3. Turbine time-averaged relative flow quantities for Case 2.

Table 4. Turbine time-averaged relative flow quantities for Case 3.

Table 5. Turbine time-averaged relative flow quantities for Case 4 . 


\begin{tabular}{|l|l|l|l|l|}
\hline Grid Type & Vane-1 & Rotor-1 & Vane-2 & Rotor-2 \\
\hline $\mathrm{O}$ & $1 \times 141 \times 31 \times 51$ & $2 \times 151 \times 21 \times 51$ & $5 \times 121 \times 31 \times 51$ & $4 \times 121 \times 31 \times 51$ \\
$\mathrm{H}$ & $1 \times 67 \times 41 \times 51$ & $2 \times 64 \times 41 \times 51$ & $5 \times 64 \times 41 \times 51$ & $4 \times 82 \times 41 \times 51$ \\
Tip & - & $2 \times 151 \times 26 \times 7$ & - & $4 \times 121 \times 16 \times 7$ \\
\hline Total Points & 363,018 & 646,054 & $1,525,625$ & $1,505,260$ \\
\hline
\end{tabular}

Table 1: Grid dimensions for the 2-stage turbine. 


\begin{tabular}{|l|l|l|l|l|}
\hline Variable & Vane-1 & Rotor-1 & Vane-2 & Rotor-2 \\
\hline$M_{\text {in }}$ & 0.08 & 0.91 & 0.59 & 0.79 \\
\hline$M_{\text {out }}$ & 1.17 & 0.85 & 1.09 & 0.81 \\
\hline$P_{\text {in }}(\mathrm{MPa})$ & 15.33 & 4.15 & 3.89 & 2.07 \\
\hline$P_{\text {out }}(\mathrm{MPa})$ & 4.15 & 3.89 & 2.07 & 1.75 \\
\hline$P t_{\text {in }}(\mathrm{MPa})$ & 15.40 & 7.79 & 4.97 & 3.16 \\
\hline$P t_{\text {out }}(\mathrm{MPa})$ & 11.10 & 6.36 & 4.35 & 2.83 \\
\hline$T t_{\text {in }}(\mathrm{K})$ & 1236. & 1111. & 1035. & 946. \\
\hline$T t_{\text {out }}(\mathrm{K})$ & 1235. & 1103. & 1029. & 944. \\
\hline$\beta_{\text {in }}(\mathrm{deg})$ & 0.0 & 60.5 & -57.1 & 56.8 \\
\hline$\beta_{\text {out }}(\mathrm{deg})$ & 63.8 & -70.1 & 67.4 & -55.2 \\
\hline$W(\mathrm{~kJ} / \mathrm{kg})$ & - & 1149. & - & 970. \\
\hline Reaction & - & 0.023 & - & 0.143 \\
\hline$\eta_{t t-\text { overall }}$ & - & - & - & 0.621 \\
\hline$\eta_{\text {ts-overall }}$ & - & - & - & 0.564 \\
\hline
\end{tabular}

Table 2: Turbine time-averaged relative flow quantities for Case 1. 


\begin{tabular}{|l|l|l|l|l|}
\hline Variable & Vane-1 & Rotor-1 & Vane-2 & Rotor-2 \\
\hline$M_{\text {in }}$ & 0.08 & 0.90 & 0.59 & 0.79 \\
\hline$M_{\text {out }}$ & 1.15 & 0.86 & 1.09 & 0.80 \\
\hline$P_{\text {in }}(\mathrm{MPa})$ & 15.33 & 4.21 & 3.86 & 2.06 \\
\hline$P_{\text {out }}(\mathrm{MPa})$ & 4.21 & 3.86 & 2.06 & 1.75 \\
\hline$P t_{\text {in }}(\mathrm{Mpa})$ & 15.40 & 7.74 & 4.95 & 3.14 \\
\hline$P t_{\text {out }}(\mathrm{Mpa})$ & 10.98 & 6.35 & 4.31 & 2.81 \\
\hline$T t_{\text {in }}(\mathrm{K})$ & 1236. & 1113. & 1036. & 948. \\
\hline$T t_{\text {out }}(\mathrm{K})$ & 1235. & 1105. & 1031. & 947. \\
\hline$\beta_{\text {in }}(\mathrm{deg})$ & 0.0 & 59.2 & -56.5 & 56.8 \\
\hline$\beta_{\text {out }}(\mathrm{deg})$ & 61.0 & -70.7 & 66.9 & -55.1 \\
\hline$W(\mathrm{~kJ} / \mathrm{kg})$ & - & 1165. & - & 965. \\
\hline$R$ Reaction & - & 0.031 & - & 0.147 \\
\hline$\eta_{\text {tt-overall }}$ & - & - & - & 0.623 \\
\hline$\eta_{\text {ts-overall }}$ & - & - & - & 0.568 \\
\hline
\end{tabular}

Table 3: Turbine time-averaged relative flow quantities for Case 2. 


\begin{tabular}{|l|l|l|l|l|}
\hline Variable & Vane-1 & Rotor-1 & Vane-2 & Rotor-2 \\
\hline$M_{\text {in }}$ & 0.08 & 0.91 & 0.59 & 0.79 \\
\hline$M_{\text {out }}$ & 1.15 & 0.86 & 1.08 & 0.85 \\
\hline$P_{\text {in }}(\mathrm{MPa})$ & 15.33 & 4.12 & 3.82 & 2.07 \\
\hline$P_{\text {out }}(\mathrm{MPa})$ & 4.12 & 3.82 & 2.07 & 1.75 \\
\hline$P t_{\text {in }}(\mathrm{MPa})$ & 15.40 & 7.67 & 4.90 & 3.12 \\
\hline$P t_{\text {out }}(\mathrm{MPa})$ & 10.87 & 6.35 & 4.29 & 2.80 \\
\hline$T t_{\text {in }}(\mathrm{MPa})$ & 1236. & 1113. & 1036. & 949. \\
\hline$T t_{\text {out }}(\mathrm{MPa})$ & 1235. & 1105. & 1032. & 947. \\
\hline$\beta_{\text {in }}(\mathrm{MPa})$ & 0.0 & 59.1 & -57.3 & 56.7 \\
\hline$\beta_{\text {out }}(\mathrm{MPa})$ & 60.0 & -70.7 & 67.5 & -55.3 \\
\hline$W(\mathrm{~kJ} / \mathrm{kg})$ & - & 1116. & - & 986. \\
\hline Reaction & - & 0.026 & - & 0.155 \\
\hline$\eta_{\text {tt-overall }}$ & - & - & - & 0.609 \\
\hline$\eta_{t s-\text { overall }}$ & - & - & - & 0.553 \\
\hline
\end{tabular}

Table 4: Turbine time-averaged relative flow quantities for Case 3. 


\begin{tabular}{|l|l|l|l|l|}
\hline Variable & Vane-1 & Rotor-1 & Vane-2 & Rotor-2 \\
\hline$M_{\text {in }}$ & 0.08 & 1.07 & 0.59 & 0.80 \\
\hline$M_{\text {out }}$ & 1.37 & 0.86 & 1.09 & 0.86 \\
\hline$P_{\text {in }}(\mathrm{MPa})$ & 15.33 & 4.15 & 3.86 & 2.07 \\
\hline$P_{\text {out }}(\mathrm{MPa})$ & 4.15 & 3.86 & 2.07 & 1.75 \\
\hline$P t_{\text {in }}(\mathrm{MPa})$ & 15.40 & 8.52 & 4.96 & 3.12 \\
\hline$P t_{\text {out }}(\mathrm{MPa})$ & 12.64 & 6.38 & 4.31 & 2.81 \\
\hline$T t_{\text {in }}(\mathrm{K})$ & 1236. & 1109. & 1035. & 948. \\
\hline$T t_{\text {out }}(\mathrm{K})$ & 1235. & 1105. & 1031. & 946. \\
\hline$\beta_{\text {in }}(\mathrm{deg})$ & 0.0 & 72.7 & -57.3 & 56.8 \\
\hline$\beta_{\text {out }}(\mathrm{deg})$ & 76.4 & -69.7 & 67.5 & -55.1 \\
\hline$W(\mathrm{~kJ} / \mathrm{kg})$ & - & 1353. & - & 991. \\
\hline$R e a c t i o n$ & - & 0.025 & - & 0.151 \\
\hline$\eta_{t t-\text { overall }}$ & - & - & - & 0.680 \\
\hline$\eta_{\text {ts-overall }}$ & - & - & - & 0.618 \\
\hline
\end{tabular}

Table 5: Turbine time-averaged relative flow quantities for Case 4. 


\section{List of Figures}

Figure 1. Endwall flowpath between first-stage vane and rotor; — Case 1, - - Case 2, - Cases 3,4.

Figure 2. Time-averaged velocity vectors - vane-1 - Case 1.

Figure 3. Time-averaged velocity vectors - vane-1 - Case 2.

Figure 4. Absolute Mach number profile - vane-1 exit.

Figure 5. Absolute Mach number profile - rotor-1 exit. 


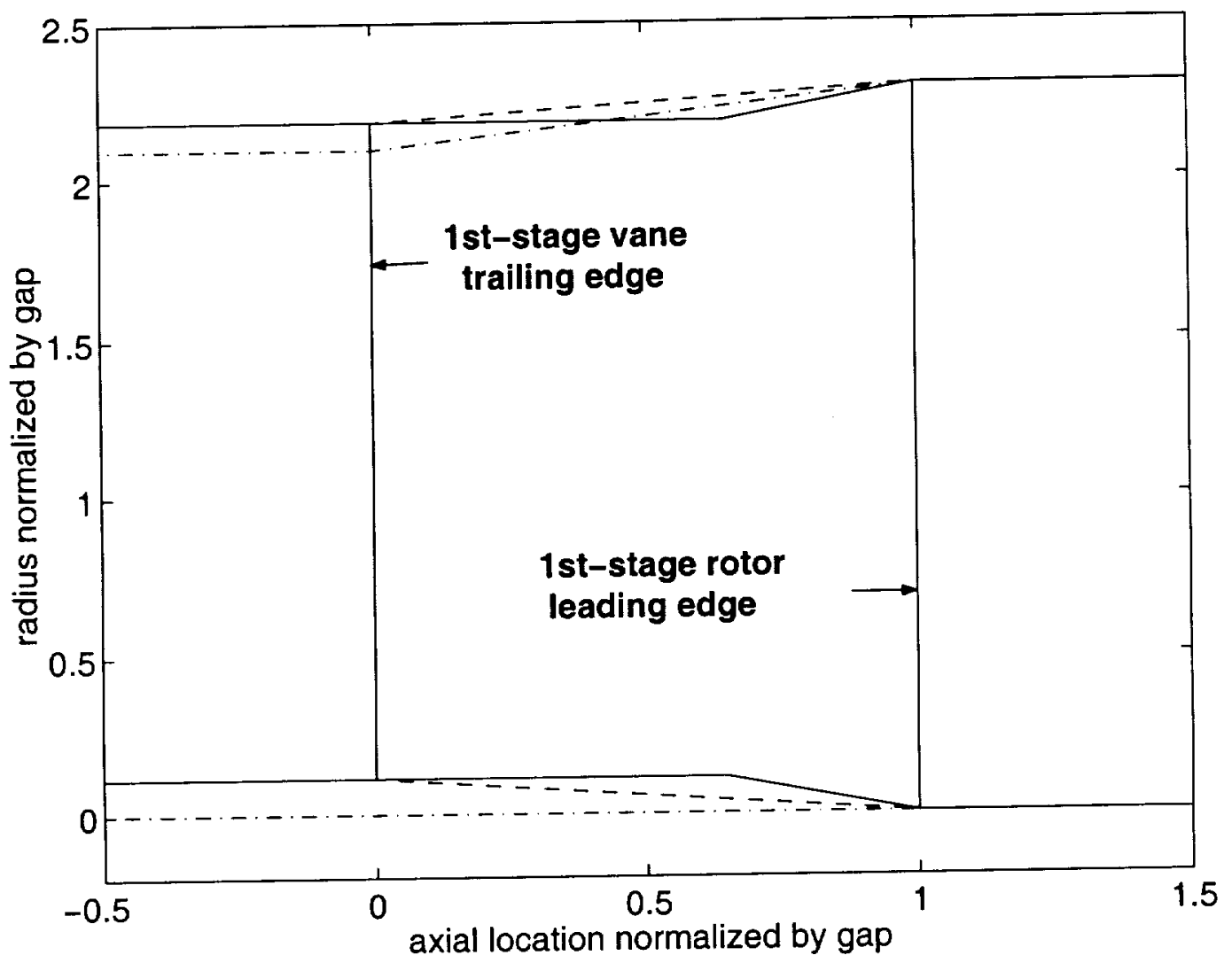

Figure 1: Endwall flowpath between first-stage vane and rotor; - Case 1, - - Case 2,--Cases 3,4. 


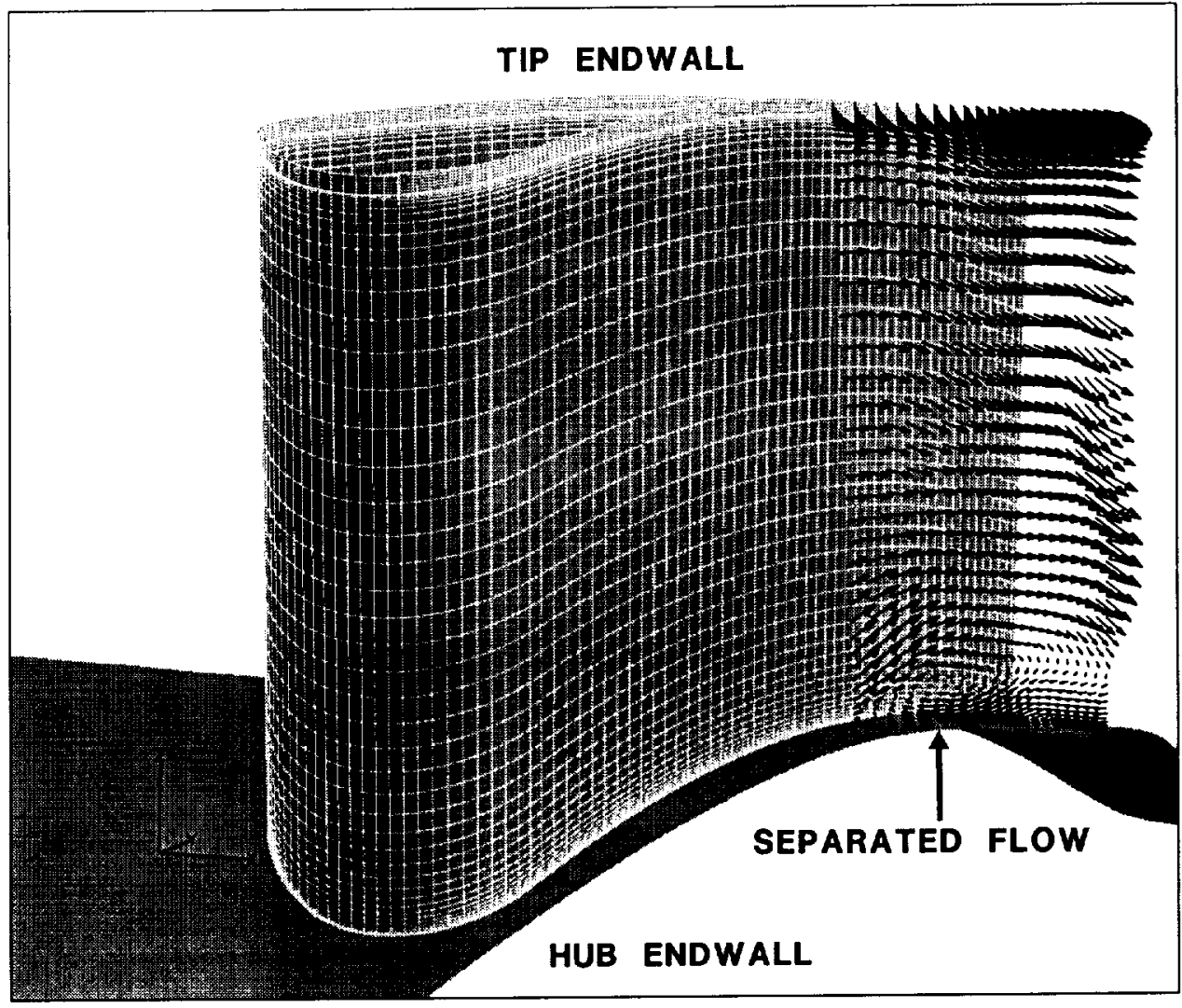

Figure 2: Time-averaged velocity vectors - vane-1 - Case 1. 


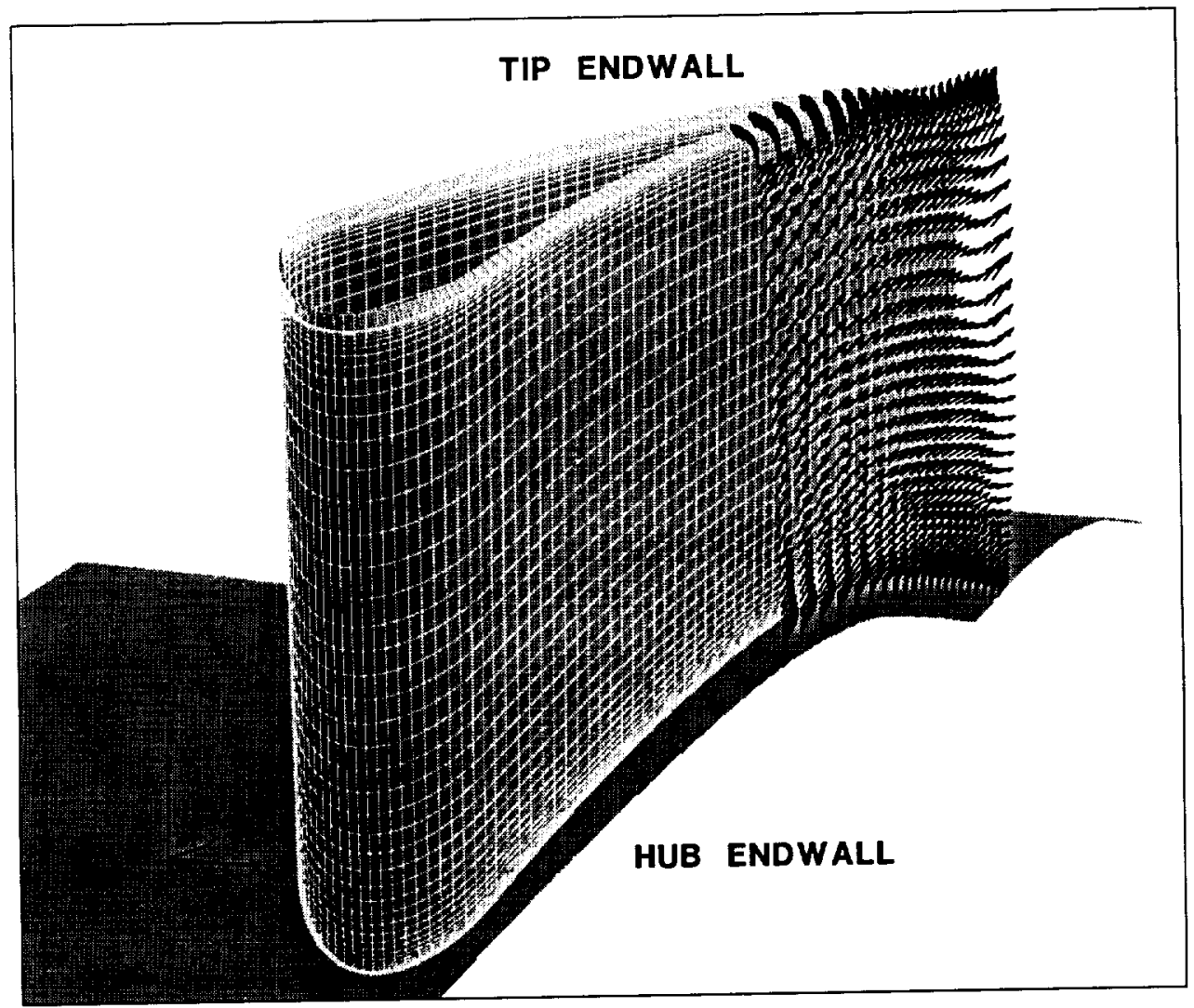

Figure 3: Time-averaged velocity vectors - vane-1 - Case 4. 


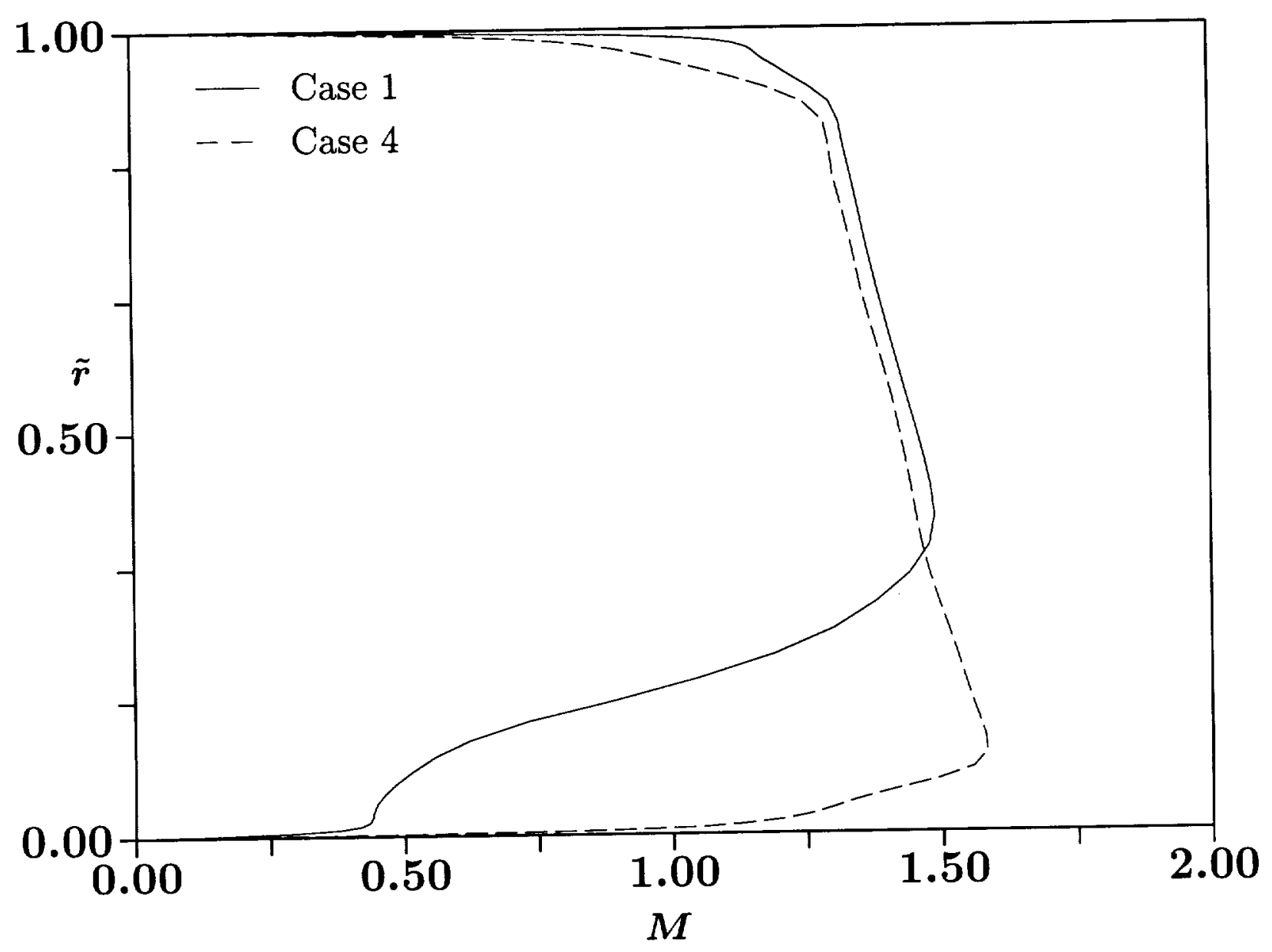

Figure 4: Absolute Mach number profile - vane-1 exit. 


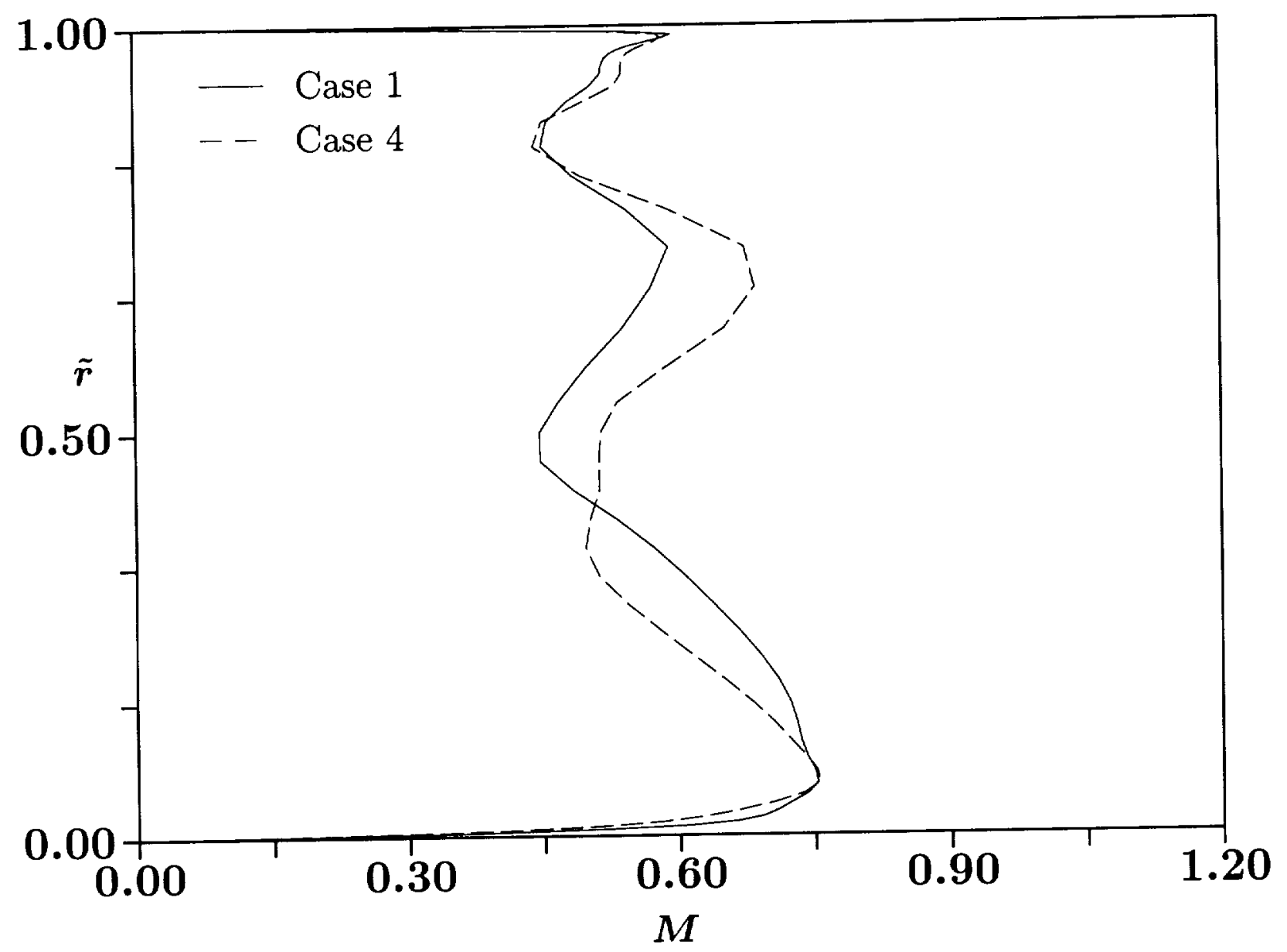

Figure 5: Absolute Mach number profile - rotor-1 exit. 